\title{
The diagnostic accuracy of median nerve ultrasonography in elderly patients with carpal tunnel syndrome: sensitivity and specificity
} assessment

This article was published in the following Dove Press journal:

Clinical Interventions in Aging

\author{
Reza Salman Roghani ${ }^{1,2}$ \\ Seyed Ebrahim Hashemi ${ }^{2}$ \\ Mohammad Taghi Holisaz ${ }^{2}$ \\ Faeze Gohari ${ }^{3}$ \\ Ahmad Delbari ${ }^{4}$ \\ Johan Lokk' \\ 'Department of Neurobiology, Care \\ Sciences and Society, Karolinska \\ Institute, Stockholm, Sweden; ${ }^{2}$ Physical \\ Medicine and Rehabilitation Research \\ Center, Shahid Beheshti University \\ of Medical Sciences, Tehran, Iran; \\ ${ }^{3}$ Student Research Committee, \\ Faculty of Medicine, Iran University of \\ Medical Sciences, Tehran, Iran; ${ }^{4}$ Iranian \\ Research Center on Aging, University \\ of Social Welfare and Rehabilitation, \\ Tehran, Iran
}

Background: Accurate diagnosis of carpal tunnel syndrome (CTS), the most common entrapment neuropathy, and its differentiation from other diseases are essential, especially in older individuals with advanced symptoms and modified electrophysiological abnormalities. The current study was conducted to evaluate the diagnostic accuracy of ultrasonography (US), regarding sensitivity and specificity in the diagnosis of CTS in elderly patients.

Methods: Individuals with upper limb complaints and reference subjects were recruited from the Rofaydeh Hospital, Tehran, Iran, from June 2013 to October 2014 - (15 months). We evaluate case and control subjects for health status, demographics, clinical characteristics of CTS, median nerve physiology by electrodiagnostic tests, and anatomy by US. Median nerve cross-sectional area (CSA) at precanal, tunnel inlet, midcanal, tunnel outlet, and antecubital levels was measured applying US examination.

Results: Of the 723 complaining patients, we assessed 380 patients with CTS symptoms. Electrodiagnostic studies (EDX) confirmed the CTS diagnosis in 203 of these clinically diseased patients. A total of 103 patients (of the 113 reference subjects) had normal EDX in the reference group. Comparisons of wrists between the afflicted and reference subjects demonstrated the CSA at precanal, tunnel inlet, midcanal, and tunnel outlet levels being significantly more abundant in the diseased hands than in the nondiseased hands. CSA at the tunnel inlet and the inlet-to-antecubital CSA ratio with a threshold of $8.5 \mathrm{~mm}^{2}$ and 0.65 gave the best diagnostic accuracy with a sensitivity and specificity of 96.9 and $93.6 \%$ for the inlet CSA and 99 and $28 \%$ for the CSA ratio, respectively.

Conclusion: The US as a noninvasive diagnostic method may serve for the investigation of CTS in elderly patients with excellent sensitivity and specificity.

Keywords: carpal tunnel syndrome, ultrasonography, electrophysiology, sensitivity, specificity

\section{Introduction}

Carpal tunnel syndrome (CTS) is a common entrapment neuropathy and potentially can lead to long-term disability. ${ }^{1,2}$ The estimated prevalence is $1 \%-5 \%$ in the general population, with a higher prevalence among women, specific occupational groups, and people older than 55 years. ${ }^{3}$ It has been shown that older age significantly affects some characteristics of peripheral nerves such as reduced expression of the major myelin proteins, demyelination, loss of myelinated and unmyelinated fibers, and delayed regeneration. ${ }^{4}$
Correspondence: Johan Lokk Department of Neurobiology, Care Sciences and Society, Karolinska Institute, Alfred Nobels Allé 23, D3 (Floor 3), Campus Huddinge (Flemingsberg),

I4I 83 Huddinge, Sweden

Tel +46858585407

Email johan.lokk@karolinska.se 
Early diagnosis is fundamental to prevent permanent sequel. ${ }^{5-7}$ The diagnosis of CTS is usually suspected when clinical symptoms (such as numbness, nocturnal paresthesia, and pain in the median nerve territory) and signs (eg, Tinel, Phalen, and Reverse Phalen signs) are present. The diagnosis has to be confirmed by electrodiagnostic studies (EDX), which is the diagnostic reference standard test. ${ }^{8,9}$ It is also conducted to determine CTS severity, an essential factor affecting long-term outcome and treatment course, and to rule out other diagnoses. ${ }^{5-7,10}$ Electrophysiological characteristics of nerves are changing with age, such as decrease conduction velocities comparing young and middle-aged groups. ${ }^{11,12}$ Consequently, EDX characteristics and normal values of nerve conduction studies (NCS) parameters are somewhat different in older ages. ${ }^{12}$ Since EDX is expensive and time-consuming and has significant falsepositive and false-negative results, a growing trend regarding other diagnostic methods has been developed. ${ }^{10,13-15}$

Although imaging methods are not employed in the routine assessment of suspected CTS, several studies have shown the potential value of ultrasonography (US) in this disease. ${ }^{16-18}$ US is a feasible, simple, rapid, accurate, inexpensive, and noninvasive method, which has been increasingly used in CTS diagnosis. ${ }^{19,20}$ However, there are still no reliable data on US of CTS in elderly patients.

The objective of the current study is to evaluate the sensitivity and specificity of median nerve US in the diagnosis of CTS in elderly patients.

\section{Methods}

\section{Subjects and design}

In this study, elderly ( $>60$ years) patients with upper limb complaints were recruited prospectively via convenience sampling from patients referred to the Physical Medicine and Rehabilitation Clinic at the Rofaydeh Hospital, Tehran, Iran, from June 2013 to October 2014. Given the absolute precision of 0.5 and an SD of 1 for the median nerve inlet cross-sectional area (CSA), as the most sensitive and specific parameter in detecting CTS, considering 80\% power and $95 \%$ CI, a sample size would be at least 63 subjects in each group. CTS was diagnosed clinically, according to the criteria of the American Academy of Neurology practice parameters. $^{21,22}$ EDX was performed for CTS confirmation and severity determination, followed by the US for detecting CSA. We did the same for subjects with the same age group without any musculoskeletal complaint as a reference group. Exclusion criteria for participation were as follows: 1) a previous history of wrist or hand trauma with bone fractures or laceration; 2) presence of neurologic disorders such as polyneuropathy, proximal median or ulnar neuropathy, plexopathy, mononeuritis multiplex, cervical radiculopathy, and cervical spondylosis; 3 ) a history of previous carpal tunnel release; 4) anatomical or structural misalignment in upper limb; and 5) other lesions within the carpal tunnel. ${ }^{5}$

We recorded the demographic data including age, weight, height, body mass index (BMI), gender, and affected hand. Forearm length, hand length, wrist perimeter, and wrist width were measured using a caliper.

Intrarater measurement reliability was tested in study subjects by having the sonographer capture and saved two unmarked images.

Ethics committee of the University of Welfare and Rehabilitation approved the study. We informed all subjects about study details and their rights, and every one filled a written informed consent. This study complies with the Declaration of Helsinki.

\section{Electrodiagnostic: EMG-NCS}

EDX was performed using a Neuropack EMG-EP measuring device (S1, MEB-9400K, 2009; Nihon Kohden Corporation, Tokyo, Japan). All studies were conducted by only one physiatrist with 25 years of experience using surface and needle electrodes. The skin and room temperature were adjusted above $32^{\circ} \mathrm{C}$ and at $25^{\circ} \mathrm{C}$, respectively.

We applied practice parameters of the American Association of Neuromuscular and Electrodiagnostic Medicine (AANEM) for suspected CTS cases. ${ }^{23} \mathrm{We}$ recorded the median antidromic sensory NCS across the wrist with a conduction distance of $13 \mathrm{~cm}$. If the antidromic median sensory study was normal, the ulnar sensory and mixed palmar orthodromic median and ulnar NCS were performed to evaluate the absolute or relative slowing of the median latency. ${ }^{23}$ All cases with suspected CTS also underwent median, ulnar, and radial motor NCS, including median and ulnar F waves, median $\mathrm{H}$ reflex, medial and lateral antebrachial cutaneous sensory NCS, and needle EMG of the upper limb to exclude other diagnostic possibilities such as cervical radiculopathy and brachial plexopathy. ${ }^{24}$ Reference values established by Dumitru and Zawarts ${ }^{25}$ were used.

The patients who had positive EDX for CTS $(n=203)$ were categorized into mild, moderate, and severe groups, based on the criteria given by Stevens ${ }^{26}$ as follows: 1) mild CTS: prolonged (relative or absolute) sensory or mixed nerve action potential (NAP) distal latency (orthodromic, antidromic, or palmar) with or without sensory nerve action potential (SNAP) amplitude below the lower standard limit, no conduction block or mild conduction block, and no thenar 
electromyography (EMG) abnormalities (if tested); 2) moderate CTS: abnormal median sensory latencies as above and (relative or absolute) prolongation of the median motor compound muscle action potential (CMAP) distal latency, conduction block may be present, and minor thenar EMG abnormalities may be present; and 3) severe CTS: prolonged median CMAP and SNAP distal latencies, with either an absent SNAP or mixed NAP, or a low-amplitude or absent thenar CMAP, conduction block may be present, and thenar EMG abnormalities often present.

\section{US}

The high-resolution US of the carpal tunnel was carried out by just one musculoskeletal sonographer who was blinded to the NCS results with 6 years of experience. The 25-Mylab ultrasound system(Esaote, Toscana, Italy) with a $10-18 \mathrm{MHz}$ multi-D lineararray transducer was employed in the study.

The sonographic wrist examination was performed with the subject sitting in a comfortable position in front of the sonographer, with $90^{\circ}$ elbow flexion, forearm on the table, hand in supination, and fingers in semiextended neutral position. The median nerve sonography was conducted as defined by the European Society of Musculoskeletal Guidelines. ${ }^{27,28}$

One longitudinal and five transverse planes in various levels were scanned as follows:

1. Precanal area (eg, the plane proximal to where nerve entering the carpal tunnel).
2. Inlet area (eg, the level of pisiform and scaphoid) (Figure 1).

3. Midcanal area (eg, midway level between inlet and outlet) (Figure 2).

4. Outlet area (eg, the level immediately deep to the distal rim of the flexor retinaculum) (Figure 3).

5. Longitudinal (eg, the plane involving the first four above sections, placing the US probe at the midline between the radius and ulna with the center of the probe at the distal wrist crease) (Figure 4)

6. Antecubital area (eg, the plane near and medial to brachial artery) (Figure 5).

Gross anatomy of the wrist for probe placement is shown in Figure 6. The CSA of median nerve was defined as an area within the nerve sheath and determined by tracing the border of the hypoechoic nerve fascicles with an electronic caliper. The software automatically calculated the area. ${ }^{19,29,30}$

\section{Statistical analyses}

We used IBM SPSS Statistics, Version 19.0 (IBM Corporation, Armonk, NY, USA) for statistical analyses and descriptive statistics for summarizing the data, depicting medians and ranges with nonparametric tests and mean and SD with parametric tests. Distribution of data was tested using the Kolmogorov-Smirnov test. An $\alpha<0.05$ was considered statistically significant. ANOVA and its post hoc tests were used to compare quantitative variables among

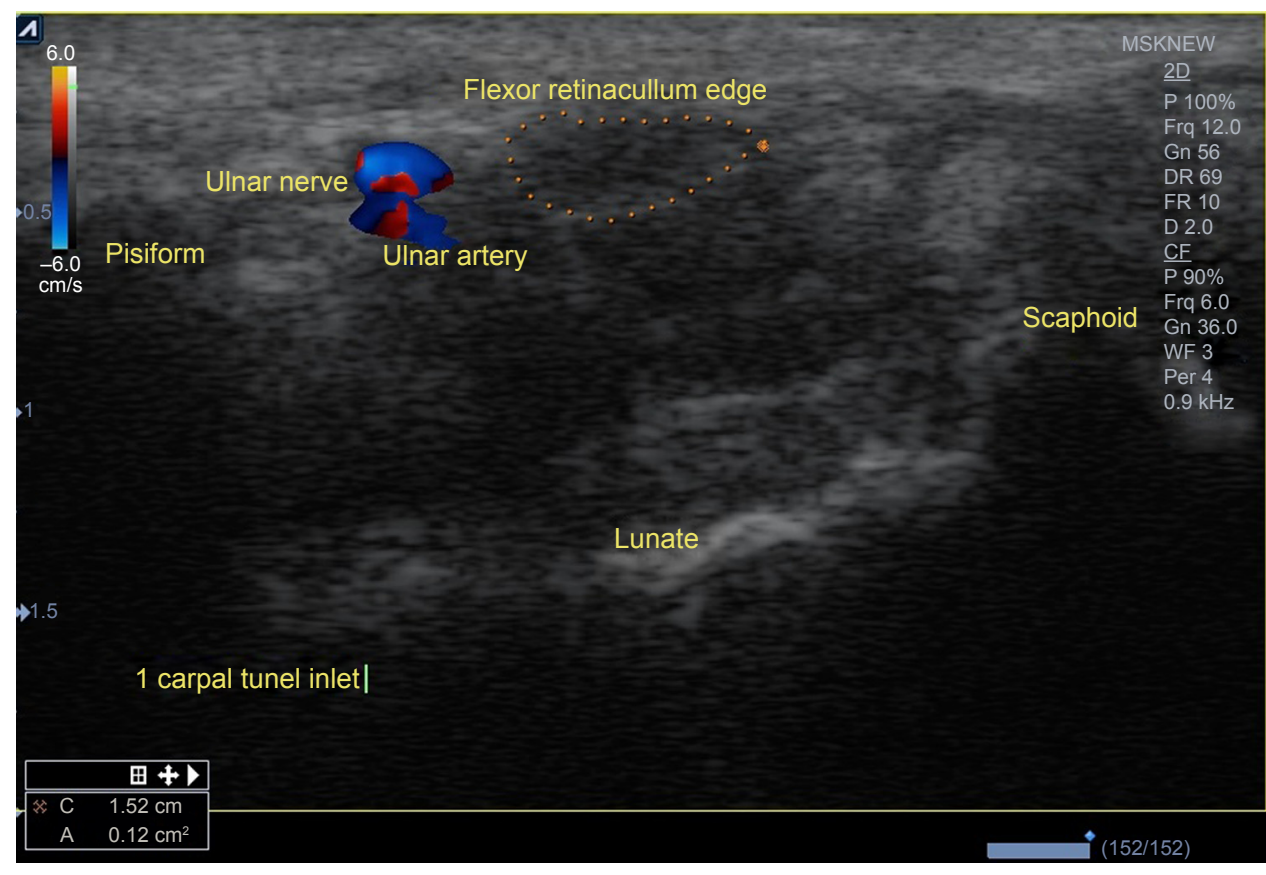

Figure I Inlet area (eg, the level of pisiform and scaphoid). 


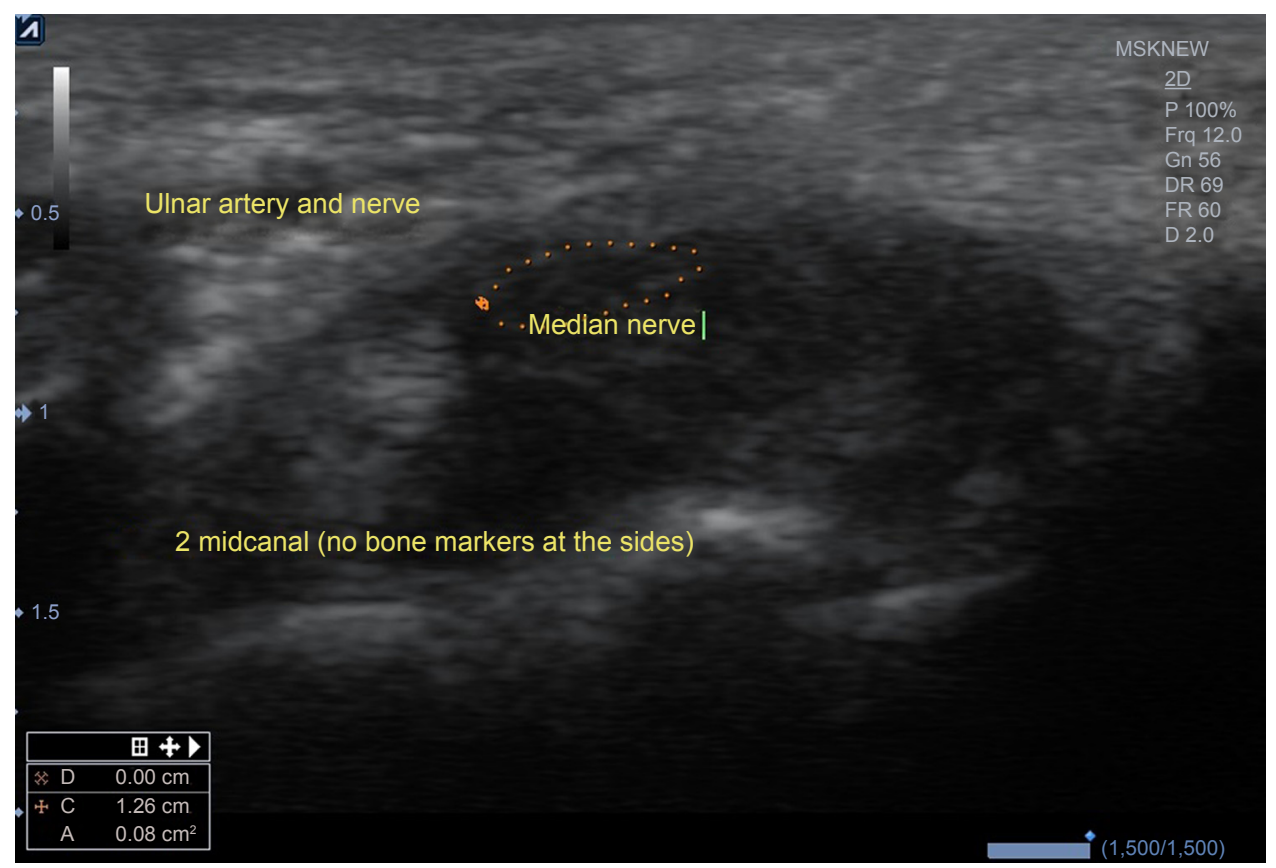

Figure 2 Midcanal area (eg, midway level between inlet and outlet).

subgroups of the study. Receiver operating characteristic (ROC) curves were also applied to determine the cutoff points of median nerve CSA and CSA ratio (in all mentioned levels). Dependability coefficient $(\varphi)$ was used for intrarater reliability.

\section{Results}

Among 723 elderly ( $>60$ years) individuals with upper limb complaints, only 380 patients were clinically suspected to have CTS. In this group, only 203 patients had abnormal EDX in favor of CTS. Among 113 subjects without any

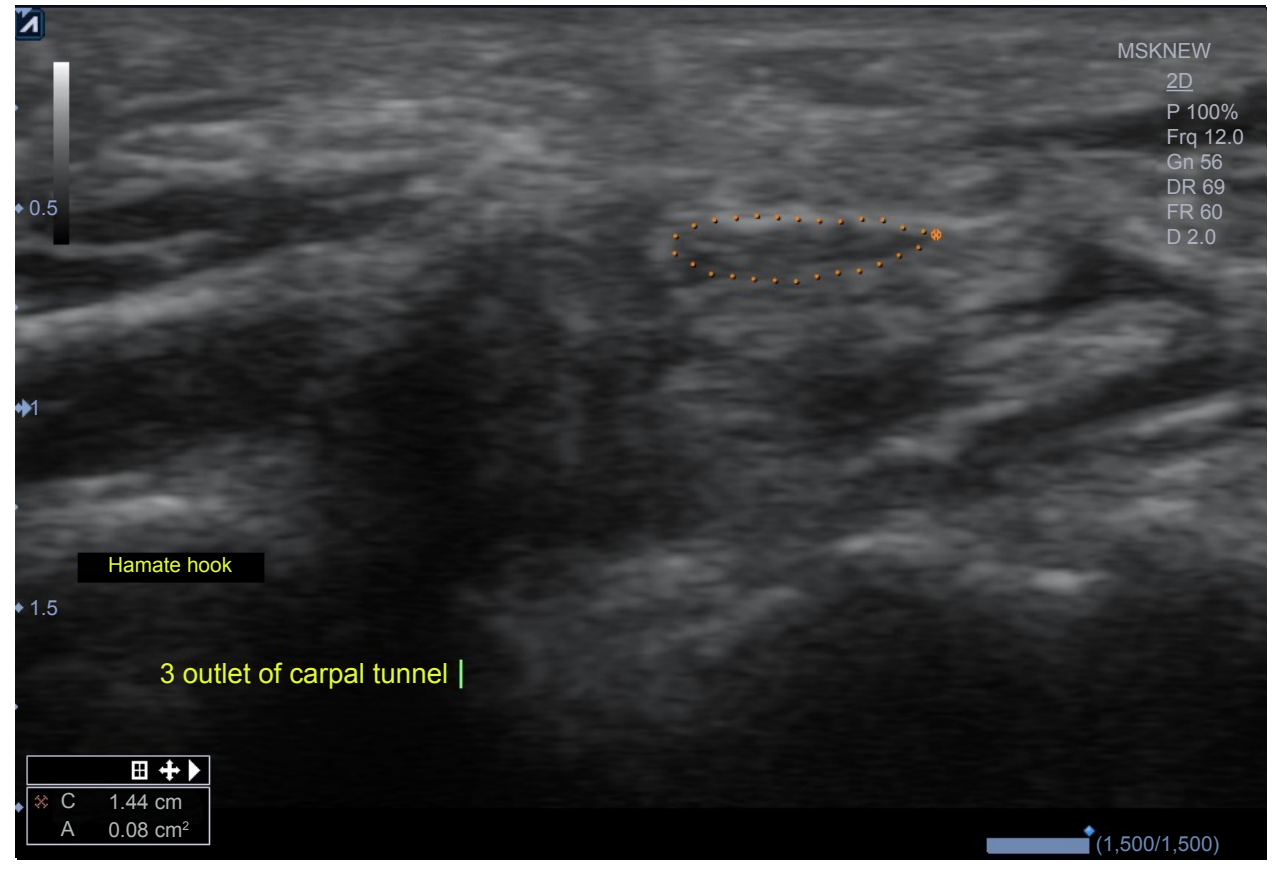

Figure 3 Outlet area (eg, the level immediately deep to the distal rim of the flexor retinaculum). 


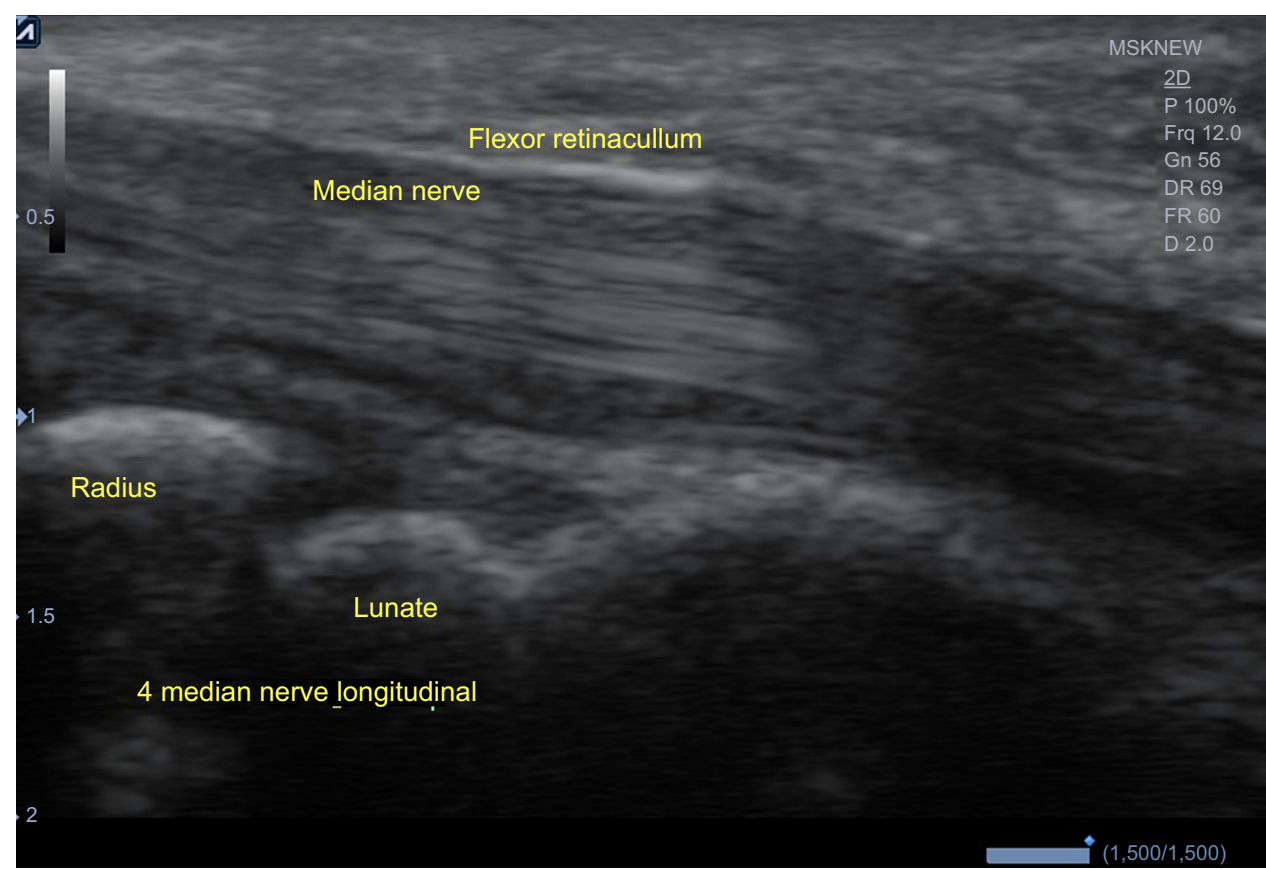

Figure 4 Longitudinal (eg, the plane involving the first four above sections, placing the ultrasonography probe at the midline between the radius and ulna with the center of the probe at the distal wrist crease).

musculoskeletal symptoms, 103 patients had completely normal EDX and considered as the reference group. Based on EDX results, we determined the severity of CTS in three abovementioned groups. All demographic data are listed in Table 1. The study design is also abstracted as a flowchart in Figure 7. The US measurements of the median nerve are summarized in Table 2.

ROC curves were used to determine the optimal discriminatory threshold values for CSA at various levels (Figure 8). When the ROC curve was fitted for sonography, the area

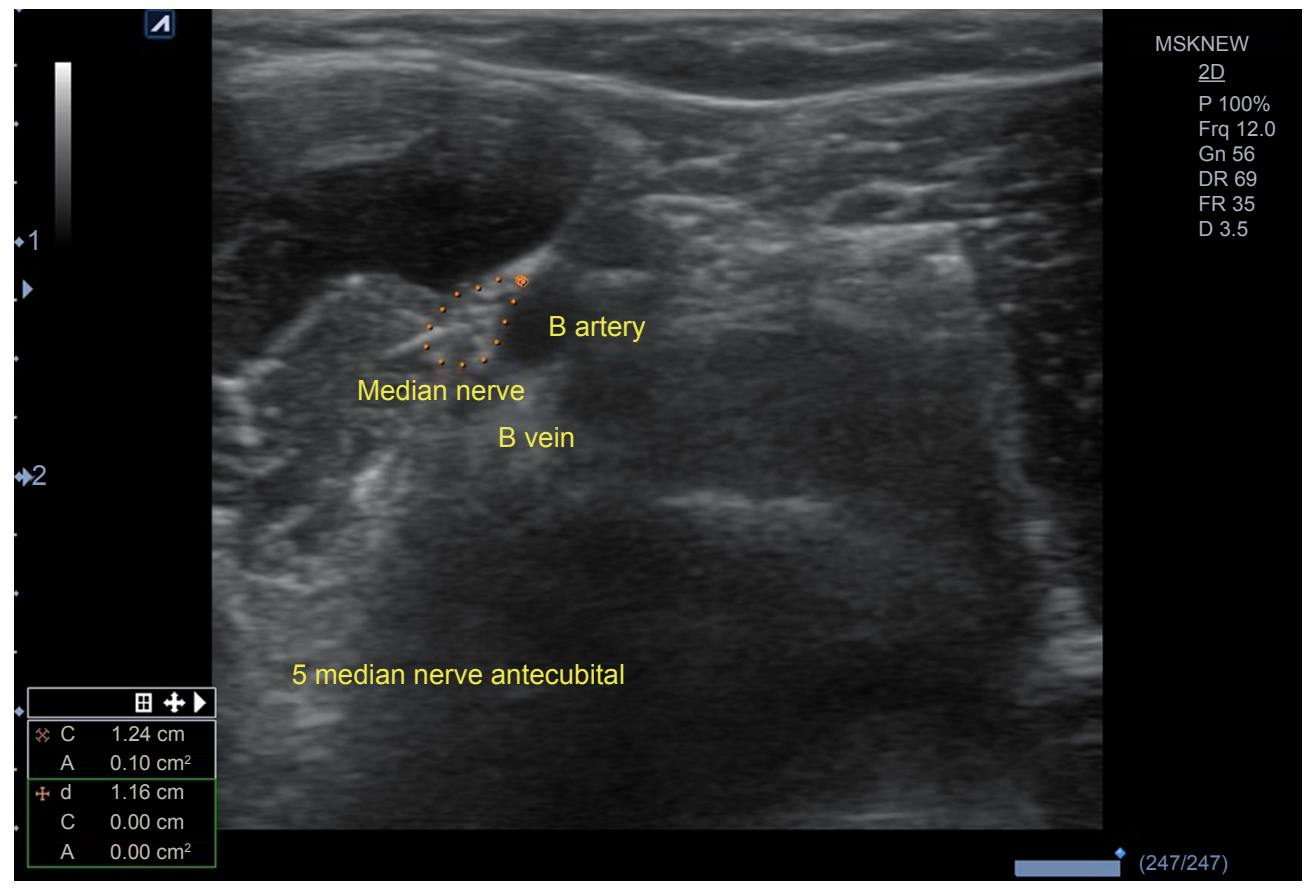

Figure 5 Antecubital area (eg, the plane near and medial to brachial artery). 




Figure 6 Gross anatomy of the wrist for carpal tunnel probe placement: I, 2, and 3 mark the cross sectional area for inlet, mid, and outlet, respectively, and 4 marks the sagittal probe placement at the wrist.

under the curve was $0.58(95 \% \mathrm{CI}, 0.52-0.65)$ for the CSA at the precarpal level, $0.98(95 \%$ CI, 0.97-0.99) for the CSA at the tunnel inlet, $0.67(95 \% \mathrm{CI}, 0.61-0.72)$ for the CSA at the midcanal level, $0.68(95 \% \mathrm{CI}, 0.63-0.74)$ for the CSA at the tunnel outlet, $0.54(95 \% \mathrm{CI}, 0.48-0.61)$ for the CSA at the antecubital level, and 0.97 (95\% CI, 0.96-0.99) for the inlet CSA/antecubital CSA ratio.

For CTS detection, CSA at the tunnel inlet with a threshold of $8.5 \mathrm{~mm}^{2}$ had $96.9 \%$ sensitivity and $93.6 \%$ specificity and the inlet/antecubital CSA ratio with a threshold of 0.65 had $99 \%$ sensitivity and $28 \%$ specificity (box plot in Figure 9). After that CSA at the tunnel outlet with a threshold of $11.5 \mathrm{~mm}^{2}$ yielded a sensitivity of $72.2 \%$ and a lower specificity of $53.2 \%$ (95\% CI, 0.626-0.743).

With the threshold of $10.5 \mathrm{~mm}^{2}$ for CSA at the precanal region, the sensitivity and specificity were 60.9 and $51.1 \%$, respectively (95\% CI, 0.519-0.649) and, with the threshold of $10.5 \mathrm{~mm}^{2}$ for CSA at the midcanal region, the sensitivity and specificity were 67.5 and $55.3 \%$, respectively. The US at the level of the antecubital region was not diagnostic with the area under the curve of 0.545 ( $P$-value 0.18 and 95\% CI, 0.482-0.609).

Intrarater reliability, as described in the "Methods" section, gave the $\varphi$ equal to 0.937 .

\section{Discussion}

Our study indicates that US examination of median nerve of older patients has an excellent diagnostic accuracy with a sensitivity and specificity of 96.9 and $93.6 \%$, respectively, for the inlet CSA and 99 and $28 \%$ for the inlet-to-antecubital CSA ratio, respectively. Additionally, our results have logically demonstrated that the mean CSA value at the midcanal level was smaller comparing to inlet and outlet CSAs. There is also a well-established association between an increased BMI and CTS as previous studies on younger population. ${ }^{31}$ However, we did not find any correlation between BMI and median CSA in the control group as our previous work. ${ }^{48}$

Hand function is essential in the activity of daily living especially in the elderly with many limitations. It is crucial to diagnose median nerve entrapment early and accurately because it is responsible for dexterities. Although electrodiagnostic studies are commonly used as the diagnostic reference standard method, its shortfalls in the diagnosis of CTS have led physicians to search for an alternative method. Nowadays, the US rapidly becomes more popular and used, mainly because of its greater accessibility, noninvasiveness, relatively low cost, and short examination times. ${ }^{32}$ Despite NCS, US does not evaluate the median nerve physiology but can assess anatomy and biomechanics of nerve such as CSA at various levels, flattening ratio, swelling ratio, bowing of the flexor retinaculum, and decreased longitudinal excursion on dynamic assessment. ${ }^{33,34}$

Table I Demographic data of the patients and control subjects

\begin{tabular}{|c|c|c|c|c|c|}
\hline Variable & $\begin{array}{l}\text { Control group } \\
N=103\end{array}$ & $\begin{array}{l}\text { Mild CTS } \\
\mathrm{N}=109\end{array}$ & $\begin{array}{l}\text { Moderate CTS } \\
\mathbf{N}=65\end{array}$ & $\begin{array}{l}\text { Severe CTS } \\
\mathbf{N}=\mathbf{2 9}\end{array}$ & P-value \\
\hline Age (years), mean $\pm S D$ & $67.9 \pm 7.9$ & $67.4 \pm 7.6$ & $68 \pm 7.2$ & $72.2 \pm 8.7$ & 0.356 \\
\hline Gender (n), female/male & $64 / 39$ & $75 / 34$ & $49 / 16$ & $24 / 5$ & 0.107 \\
\hline Affected side $(n)$, right/left & $49 / 54$ & $63 / 46$ & $33 / 32$ & $12 / 17$ & 0.315 \\
\hline Weight $(\mathrm{kg})$, mean $\pm \mathrm{SD}$ & $71.4 \pm 10$ & $76.7 \pm 10$ & $73.8 \pm 12.3$ & $72.3 \pm 15.1$ & $0.015^{*}$ \\
\hline Height $(\mathrm{cm})$, mean $\pm \mathrm{SD}$ & $165.4 \pm 8.7$ & $163 \pm 9.6$ & $159.6 \pm 8.3$ & $156 \pm 7.7$ & $<0.001 *$ \\
\hline $\mathrm{BMI}\left(\mathrm{kg} / \mathrm{m}^{2}\right)$, mean $\pm \mathrm{SD}$ & $23.7 \pm 3.6$ & $26 \pm 3.2$ & $25.5 \pm 3.9$ & $25.9 \pm 4.9$ & $<0.001 *$ \\
\hline
\end{tabular}




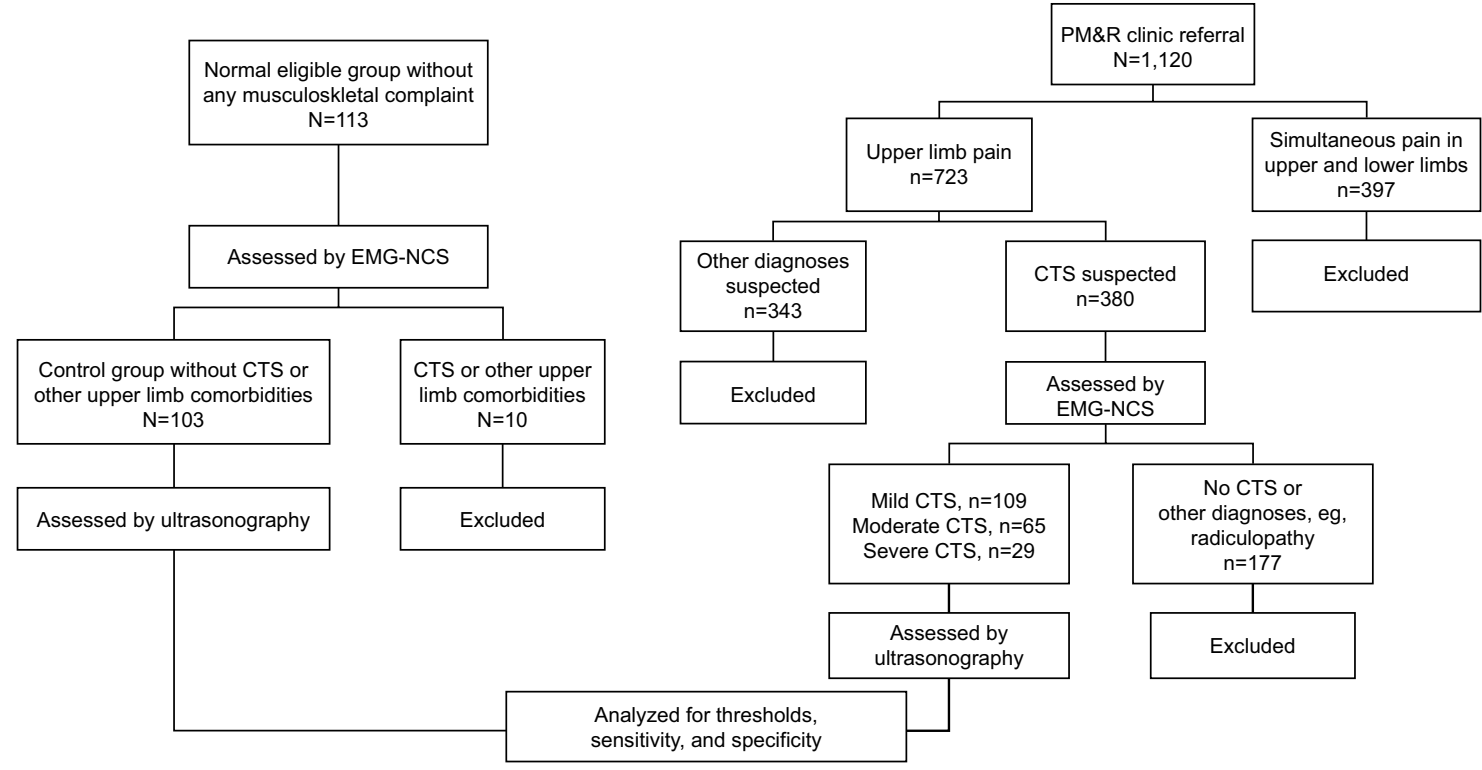

Figure 7 Study design flowchart.

Abbreviations: CTS, carpal tunnel syndrome; EMG, electromyography; NCS, nerve conduction studies; PM\&R, physical medicine and rehabilitation.

Elderly patients with CTS tend to have advanced symptoms, ${ }^{11,35}$ and this was supported by the peripheral nerve slow conduction velocity. ${ }^{36}$ Aging affects axonal integrity, and fibers' myelination leads to decrease NCV and mild abnormality in EMG even in symptom-free persons. ${ }^{36}$ It may be reported as sub-clinical CTS or considered as false positive. In contrast, we reported in our previous work that NCV has $27 \%$ false negative in our laboratory to detect CTS in clinically confirmed CTS patients. ${ }^{48}$ The correlation between age and clinical manifestation of CTS has not been established. A study showed a positive correlation between age and limitation of hand function but not between the age and the severity of symptoms. ${ }^{37}$ Blumenthal et al's ${ }^{12}$ study showed that electrophysiological abnormalities of CTS were 3.2 times more common in patients over the age of 65 years with mild CTS symptoms than in younger patients, suggesting that older patients faced worse CTS but may underreport their clinical symptoms. However, the reported cutoff age to indicate elderly changes in CTS patients also varies among studies, ranging from 55 to 80 years. ${ }^{38}$ It is crucial to have a sensitive and accurate screening method, helping the elderly to be diagnosed and treated as soon as possible.

The wide variation in sensitivities and specificities of median nerve US for CTS detection has been reported in the general population. In a meta-analysis, the pooled sensitivity and specificity of US for the CTS diagnosis were $77.6 \%$ (95\% CI 71.6\%-83.6\%) and 86.8\% (95\% CI 78.9\%-94.8\%), respectively, regardless of the reference standard used. ${ }^{5}$ The sensitivity reported in applied studies ranged from $57 \%$ to $98 \%$, and the specificity ranged from $63 \%$ to $100 \%$. The pooled sensitivity and specificity were $77.3 \%(95 \%$ CI $62.1 \%-84.6 \%$ ) and $92.8 \%$ (95\% CI $81.3 \%-100 \%)$,

Table 2 Mean median nerve CSA $\left(\mathrm{mm}^{2}\right) \pm$ SD in different carpal tunnel levels

\begin{tabular}{|c|c|c|c|c|c|}
\hline Ultrasonographic measurements & Mild CTS & Moderate CTS & Severe CTS & Control group & $P$-value \\
\hline Precanal CSA $\left(\mathrm{mm}^{2}\right)$, mean $\pm \mathrm{SD}$ & $11.2 \pm 2.1$ & $12 \pm 2.8$ & $14 \pm 2.8$ & $10.8 \pm 2.3$ & $<0.001$ \\
\hline Inlet CSA $\left(\mathrm{mm}^{2}\right)$, mean \pm SD & $12.8 \pm 2.6$ & $13.9 \pm 3.9$ & $14.6 \pm 4.6$ & $7 \pm 1$ & $<0.001$ \\
\hline Midcanal CSA $\left(\mathrm{mm}^{2}\right)$, mean \pm SD & $11.7 \pm 2.2$ & $12.8 \pm 3.4$ & $14 \pm 3.6$ & $10.3 \pm 2.2$ & $<0.001$ \\
\hline Outlet CSA $\left(\mathrm{mm}^{2}\right)$, mean \pm SD & $12.9 \pm 2.4$ & $13.9 \pm 3$ & $14.9 \pm 3.5$ & $11.2 \pm 2.5$ & $<0.001$ \\
\hline Antecubital CSA $\left(\mathrm{mm}^{2}\right)$, mean $\pm \mathrm{SD}$ & $9.7 \pm 1.4$ & $9.7 \pm 1.1$ & $10.1 \pm 1$ & $9.5 \pm 1.1$ & 0.194 \\
\hline Flexor retinaculum thickness $(\mathrm{mm})$, mean $\pm \mathrm{SD}$ & $2.22 \pm 0.5$ & $2.25 \pm 0.49$ & $2.20 \pm 0.31$ & $2.19 \pm 0.54$ & 0.886 \\
\hline Precanal CSA $\left(\mathrm{mm}^{2}\right) /$ outlet CSA $\left(\mathrm{mm}^{2}\right)$, mean $\pm \mathrm{SD}$ & $0.86 \pm 0.20$ & $0.88 \pm 0.17$ & $0.91 \pm 0.22$ & $0.95 \pm 0.28$ & 0.044 \\
\hline Precanal CSA $\left(\mathrm{mm}^{2}\right) /$ antecubital CSA $\left(\mathrm{mm}^{2}\right)$, mean \pm SD & $1.13 \pm 0.29$ & $1.22 \pm 0.31$ & $1.34 \pm 0.38$ & $1.09 \pm 0.31$ & $<0.001$ \\
\hline Inlet CSA $\left(\mathrm{mm}^{2}\right)$ /outlet CSA $\left(\mathrm{mm}^{2}\right)$, mean \pm SD & $\mathrm{I} \pm 0 . \mathrm{I}$ & $\mathrm{I} \pm 0.2$ & $0.97 \pm 0.19$ & $0.67 \pm 0.19$ & $<0.001$ \\
\hline Inlet CSA $\left(\mathrm{mm}^{2}\right) /$ antecubital CSA $\left(\mathrm{mm}^{2}\right)$, mean $\pm \mathrm{SD}$ & $1.33 \pm 0.3$ & $1.43 \pm 0.45$ & $1.44 \pm 0.42$ & $0.74 \pm 0.14$ & $<0.001$ \\
\hline
\end{tabular}

Abbreviations: CSA, cross-sectional area; CTS, carpal tunnel syndrome. 


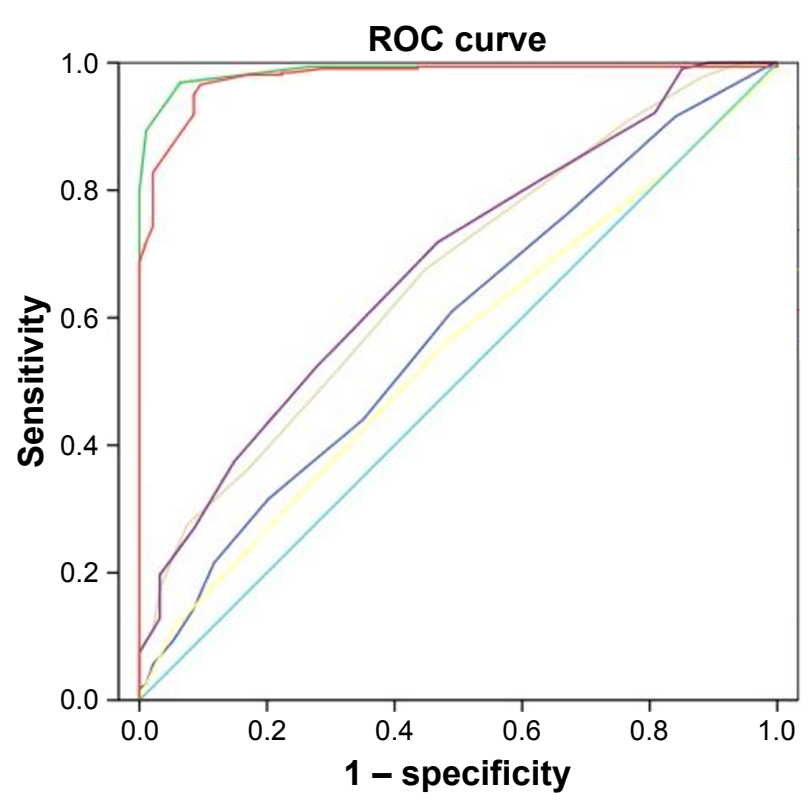

\begin{tabular}{|ll|}
\hline $\begin{array}{l}\text { Source of the curve } \\
-\mathrm{CSA}\left(\mathrm{mm}^{2}\right) \text { at the precanal } \\
\text { level }\end{array}$ & $\begin{array}{l}\text { CSA }\left(\mathrm{mm}^{2}\right) \text { at the } \\
\text { antecubital level }\end{array}$ \\
$-\mathrm{CSA}\left(\mathrm{mm}^{2}\right)$ at the inlet level & $\begin{array}{l}\text { Inlet CSA }\left(\mathrm{mm}^{2}\right) / \\
\text { antecubital CSA }\left(\mathrm{mm}^{2}\right)\end{array}$ \\
- CSA $\left(\mathrm{mm}^{2}\right)$ at the midcanal & - Reference line \\
level & \\
- CSA $\left(\mathrm{mm}^{2}\right)$ at the outlet \\
level
\end{tabular}

Figure 8 ROC curve for ultrasonographic assessments of median nerve CSA at the carpal tunnel.

Abbreviations: CSA, cross-sectional area; ROC, receiver operating characteristics.

respectively, using the clinical diagnosis as the reference standard. ${ }^{39}$ The pooled sensitivity and specificity using NCS as the gold standard were $80.2 \%$ (95\% CI $71.3 \%-89.0 \%$ ) and $78.7 \%$ (95\% CI 66.4\%-91.1\%), respectively. ${ }^{39}$ It is showed that NCS may still not be replaced by the US. Instead, it is suggested as a potential part of an algorithm in which US is an initial step in the evaluation of patients suspected with CTS, where electrodiagnostic tests only are performed if the US results were nonconfirmatory. ${ }^{5,6,8,39}$ There are also different reports on the mean normal values of median nerve CSA at the carpal tunnel inlet, ranging from 6.1 to $10.4 \mathrm{~mm}^{2} .{ }^{8}$

These discrepancies may have several reasons: selection criteria of patients and controls, the reference standard for the diagnosis of CTS, electrodiagnostic criteria of CTS diagnosis, sonography techniques, experience of sonographer, and intrarater and inter-rater reliabilities of median nerve CSA measurements at various levels among studies. Some studies demonstrated that different demographic characteristics, such as older age, male gender, BMI, and handedness, may contribute to the range of mean normal values of median nerve CSA at the carpal tunnel inlet. However, another study found no significant association between biometric features of subjects and median nerve CSA at wrist and forearm. ${ }^{40}$ The reference standard for CTS diagnosis varies among studies, some of which employ clinical and abnormal electrodiagnostic tests and the others benefited from clinical findings only. ${ }^{40} \mathrm{An}$ inherent weakness of the studies using only clinical diagnosis is the use of asymptomatic control subjects, whom may still have median nerve disorder but are not yet symptomatic. Moreover, the NCS criteria for CTS diagnosis have significant variation among studies, responsible for broad-ranged sensitivity and specificity.

There is still no systematic review to assess and compare both the intrarater and inter-rater reliabilities of median nerve CSA measurements at various levels. However, in almost all studies, only a single sonographer was employed to capture and trace the images. Thus, it may be ignored. ${ }^{9}$ Such variability
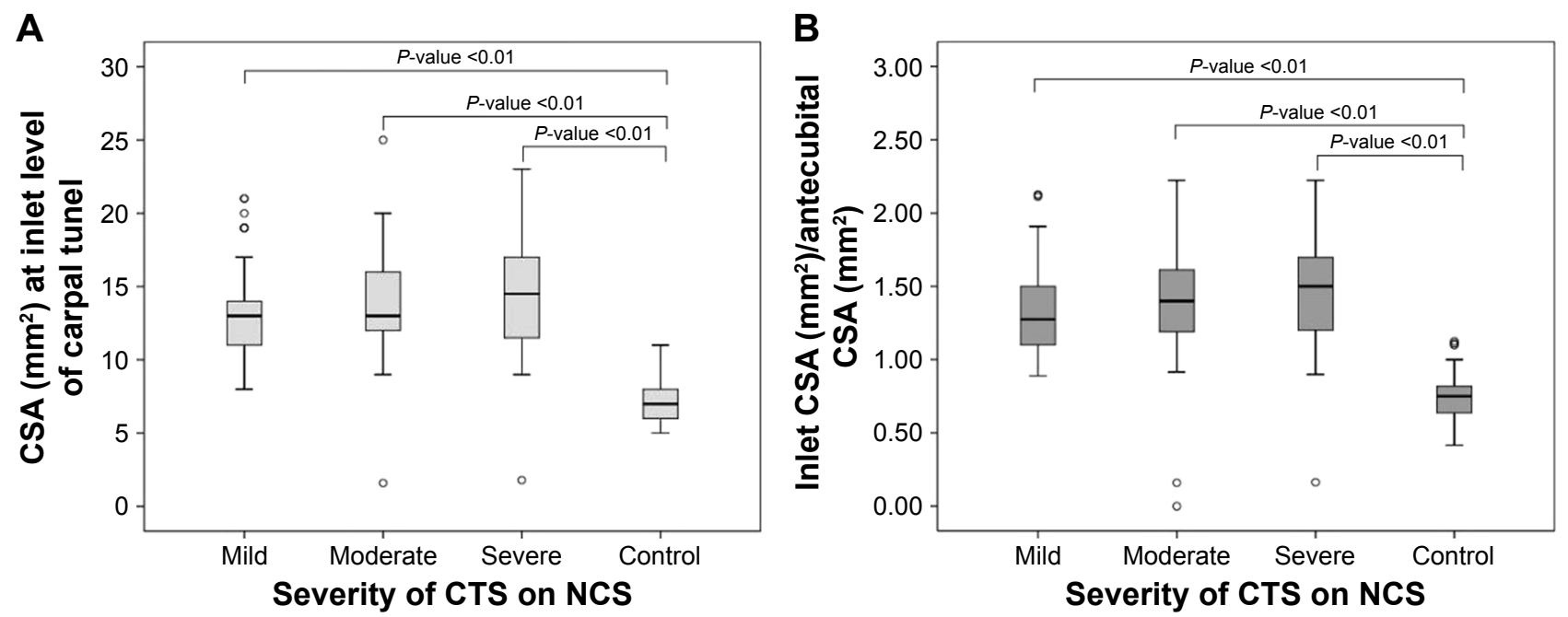

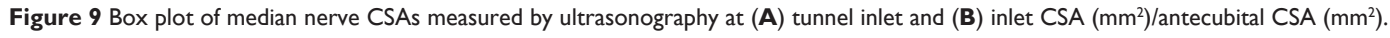
Abbreviations: CSA, cross-sectional area; CTS, carpal tunnel syndrome; NCS, nerve conduction studies. 
in the reliability of median nerve CSA measurements at various levels in conducted studies and being indifferent to it can also justify the observed wide ranges of measurements.

Confirming our study, a meta-analysis and some literature reviews demonstrated that the median nerve CSA at the carpal tunnel inlet (at the level of the pisiform) gives the most accurate single diagnostic criterion for evaluating patients with suspected CTS, with highest sensitivity and specificity. ${ }^{41-43}$ A disagreement on the exact localization of the tunnel inlet also exists in which some sonographers assume the proximal edge of the flexor retinaculum, at the level of distal radioulnar joint, to be the tunnel inlet while others consider the pisiform bone and scaphoid bone as the landmark, which we also used. ${ }^{44}$

To overcome the limitations arising from subjects' anatomical variations, some parameters including "wrist-toforearm median CSA ratios," "wrist-to-forearm CSA difference," and "nerve tunnel index" have been developed. ${ }^{30,45-47}$ However, the debate and further studies have been suggested. Accordingly, we calculated the inlet-to-antecubital CSA ratio, which was a robustly and accurately diagnostic measurement with the area under the curve and the threshold of 0.97 (95\% CI, 0.96-0.99) and 0.65, respectively. Given that the sensitivity and specificity were 99 and $28 \%$, respectively.

\section{Limitations}

Our study is not without limitations. We did not assess flattening ratio, swelling ratio, palmar bowing of the flexor retinaculum, and longitudinal excursion on dynamic assessment. We did not reach the 63 target size in the severe CTS group due to limited resources, which should be addressed in the future. We also believe that additional studies are necessary to determine the role of US for patients with clinical symptoms of CTS, but with negative NCS studies or suffering from simultaneous diagnoses, eg, radiculopathy. Neither any of the reviewed studies nor our study compares the results of old individuals with younger patients, and a control group of younger patients was not found in all these studies. The strengths of our study are the prospective design and the inclusion of elderly patients who were newly diagnosed, the diagnosis is confirmed by clinical and NCS findings, and the inclusion of asymptomatic controls has negative NCS results. Moreover, further strengths of our study are the wrist-to-forearm median CSA ratio allowing more accurate detection of CTS together with reporting the intrarater reliability.

\section{Conclusion}

We proved that the US as a noninvasive and convenient test might serve as a diagnostic method for the investigation of CTS in the elderly patients. They may suffer from multiple disorders, which may contribute to the experience of unpleasant diagnostic and therapeutic interventions. Additionally, we demonstrated that the inlet CSA and inlet-to-antecubital CSA ratio are precise diagnostic measurements among which the inlet CSA has $96.9 \%$ sensitivity and $93.6 \%$ specificity and the inlet/antecubital CSA ratio has $99 \%$ sensitivity and $28 \%$ specificity. We believe that US is a helpful method in the screening of elderly persons with minimal hand symptoms to address the issue before severe complications.

\section{Acknowledgments}

The study was supported by a grant from Physical Medicine and Rehabilitation Research Center, Shahid Beheshti University of Medical Sciences, Tehran, Iran. Also, we would like to thank all the participants for their collaborations.

\section{Disclosure}

The authors report no conflicts of interest in this work.

\section{References}

1. Barcenilla A, March LM, Chen JS, Sambrook PN. Carpal tunnel syndrome and its relationship to occupation: a meta-analysis. Rheumatology. 2012;51(2):250-261.

2. Alfonso C, Jann S, Massa R, Torreggiani A. Diagnosis, treatment and follow-up of the carpal tunnel syndrome: a review. Neurol Sci. 2010; 31(3):243-252.

3. Atroshi I, Gummesson C, Johnsson R, Ornstein E, Ranstam J, Rosén I. Prevalence of carpal tunnel syndrome in a general population. JAMA. 1999;282(2):153-158.

4. Vyšata $O$, Procházka A, Kunc $P$, et al. Age delays the recovery of distal motor latency after carpal tunnel syndrome surgery. Acta Neurochir. 2014; 156(7):1335-1339.

5. Fowler JR, Gaughan JP, Ilyas AM. The sensitivity and specificity of ultrasound for the diagnosis of carpal tunnel syndrome: a meta-analysis. Clin Orthop Relat Res. 2011;469(4):1089-1094.

6. Descatha A, Huard L, Duval S. Letter to the Editor: The Sensitivity and Specificity of Ultrasound for the Diagnosis of Carpal Tunnel Syndrome: A Meta-analysis. Clin Orthop and Relat Res. 2011;469(3):901-902.

7. Klauser AS, Halpern EJ, de Zordo T, et al. Carpal tunnel syndrome assessment with US: value of additional cross-sectional area measurements of the median nerve in patients versus healthy volunteers. Radiology. 2009;250(1):171-177.

8. Wong SM, Griffith JF, Hui AC, Lo SK, Fu M, Wong KS. Carpal tunnel syndrome: diagnostic usefulness of sonography. Radiology. 2004; 232(1):93-99.

9. Impink BG, Gagnon D, Collinger JL, Boninger ML. Repeatability of ultrasonographic median nerve measures. Muscle Nerve. 2010;41(6): 767-773.

10. Jablecki CK, Andary MT, Floeter MK, et al. Practice parameter: Electrodiagnostic studies in carpal tunnel syndrome. Report of the American Association of Electrodiagnostic Medicine, American Academy of Neurology, and the American Academy of Physical Medicine and Rehabilitation. Neurology. 2002;58(11):1589-1592.

11. Bland JD, Rudolfer SM. Clinical surveillance of carpal tunnel syndrome in two areas of the United Kingdom, 1991-2001. J Neurol Neurosurg Psychiatry. 2003;74(12):1674-1679.

12. Blumenthal S, Herskovitz S, Verghese J. Carpal tunnel syndrome in older adults. Muscle Nerve. 2006;34(1):78-83.

13. Wang L. Electrodiagnosis of carpal tunnel syndrome. Phys Med Rehabil Clin N Am. 2013;24(1):67-77. 
14. Atroshi I, Gummesson C, Johnsson R, Ornstein E. Diagnostic properties of nerve conduction tests in population-based carpal tunnel syndrome. BMC Musculoskelet Disord. 2003;4:9.

15. Lew HL, Date ES, Pan SS, Wu P, Ware PF, Kingery WS. Sensitivity, specificity, and variability of nerve conduction velocity measurements in carpal tunnel syndrome. Arch Phys Med Rehabil. 2005;86(1):12-16.

16. Wiesler ER, Chloros GD, Cartwright MS, Smith BP, Rushing J, Walker FO. The use of diagnostic ultrasound in carpal tunnel syndrome. $J$ Hand Surg Am. 2006;31(5):726-732.

17. Pinilla I, Martín-Hervás C, Sordo G, Santiago S. The usefulness of ultrasonography in the diagnosis of carpal tunnel syndrome. J Hand Surg Eur Vol. 2008;33(4):435-439.

18. Ashraf AR, Jali R, Moghtaderi AR, Yazdani AH. The diagnostic value of ultrasonography in patients with electrophysiologicaly confirmed carpal tunnel syndrome. Electromyogr Clin Neurophysiol. 2009;49(1):3-8.

19. Mhoon JT, Juel VC, Hobson-Webb LD. Median nerve ultrasound as a screening tool in carpal tunnel syndrome: Correlation of cross-sectional area measures with electrodiagnostic abnormality. Muscle Nerve. 2012; 46(6):861-870.

20. Ajeena IM, Al-Saad RH, Al-Mudhafar A, Hadi NR, Al-Aridhy SH. Ultrasonic assessment of females with carpal tunnel syndrome proved by nerve conduction study. Neural Plast. 2013;2013:754564.

21. You H, Simmons Z, Freivalds A, Kothari MJ, Naidu SH. Relationships between clinical symptom severity scales and nerve conduction measures in carpal tunnel syndrome. Muscle Nerve. 1999;22(4): 497-501.

22. Practice parameter for carpal tunnel syndrome (summary statement). Report of the Quality Standards Subcommittee of the American Academy of Neurology. Neurology. 1993;43(11):2406-2409.

23. Jablecki CK, Andary MT, Floeter MK, et al. Practice parameter: Electrodiagnostic studies in carpal tunnel syndrome. Report of the American Association of Electrodiagnostic Medicine, American Academy of Neurology, and the American Academy of Physical Medicine and Rehabilitation. Neurology. 2002;58(11):1589-1592.

24. Werner RA, Andary M. Electrodiagnostic evaluation of carpal tunnel syndrome. Muscle Nerve. 2011;44(4):597-607.

25. Dumitru D, Zawarts MJ. Electrodiagnostic Medicine. Philadelphia, PA: Hanley \& Belfus; 2002:1060.

26. Stevens JC. AAEM minimonograph \#26: the electrodiagnosis of carpal tunnel syndrome. American Association of Electrodiagnostic Medicine. Muscle Nerve. 1997;20(12):1477-1486.

27. Cannella AC, Kissin EY, Torralba KD, Higgs JB, Kaeley GS. Evolution of musculoskeletal ultrasound in the United States: implementation and practice in rheumatology. Arthritis Care Res. 2014;66(1):7-13.

28. Backhaus M, Burmester GR, Gerber T, et al. Guidelines for musculoskeletal ultrasound in rheumatology. Ann Rheum Dis. 2001;60(7): 641-649.

29. Pimentel BF, Abicalaf CA, Braga L, et al. Cross-sectional area of the median nerve characterized by ultrasound in patients with carpal tunnel syndrome before and after the release of the transverse carpal ligament. Journal of Diagnostic Medical Sonography. 2013;29(3):116-121.

30. Klauser AS, Abd Ellah MM, Halpern EJ, et al. Sonographic crosssectional area measurement in carpal tunnel syndrome patients: can delta and ratio calculations predict severity compared to nerve conduction studies? Eur Radiol. 2015;25(8):2419-2427.
31. Junck AD, Escobedo EM, Lipa BM, et al. Reliability Assessment of Various Sonographic Techniques for Evaluating Carpal Tunnel Syndrome. J Ultrasound Med. 2015;34(11):2077-2088.

32. Koyuncuoglu HR, Kutluhan S, Yesildag A, Oyar O, Guler K, Ozden A. The value of ultrasonographic measurement in carpal tunnel syndrome in patients with negative electrodiagnostic tests. Eur J Radiol. 2005; 56(3):365-369.

33. Sernik RA, AbicalafCA, Pimentel BF, Braga-Baiak A, Braga L, Cerri GG. Ultrasound features of carpal tunnel syndrome: a prospective casecontrol study. Skeletal Radiol. 2008;37(1):49-53.

34. Hough AD, Moore AP, Jones MP. Reduced longitudinal excursion of the median nerve in carpal tunnel syndrome. Arch Phys Med Rehabil. 2007;88(5):569-576.

35. Seror P. Carpal tunnel syndrome in the elderly. "Beware of severe cases”. Ann Chir Main Memb Super. 1991;10(3):217-225.

36. Verdú E, Ceballos D, Vilches JJ, Navarro X. Influence of aging on peripheral nerve function and regeneration. J Peripher Nerv Syst. 2000; 5(4):191-208.

37. Padua L, Padua R, Lo Monaco M, Aprile I, Tonali P. Multiperspective assessment of carpal tunnel syndrome: a multicenter study. Italian CTS Study Group. Neurology. 1999;53(8):1654-1659.

38. Fung BW, Tang CY, Fung BK. Does aging matter? The efficacy of carpal tunnel release in the elderly. Arch Plast Surg. 2015;42(3):278-281.

39. Descatha A, Huard L, Aubert F, Barbato B, Gorand O, Chastang JF. Meta-analysis on the performance of sonography for the diagnosis of carpal tunnel syndrome. Semin Arthritis Rheum. 2012;41(6):914-922.

40. El Miedany YM, Aty SA, Ashour S. Ultrasonography versus nerve conduction study in patients with carpal tunnel syndrome: substantive or complementary tests? Rheumatology. 2004;43(7):887-895.

41. Beekman R, Visser LH. Sonography in the diagnosis of carpal tunnel syndrome: a critical review of the literature. Muscle Nerve. 2003;27(1): 26-33.

42. Roll SC, Case-Smith J, Evans KD. Diagnostic accuracy of ultrasonography vs. electromyography in carpal tunnel syndrome: a systematic review of literature. Ultrasound Med Biol. 2011;37(10):1539-1553.

43. Tai TW, Wu CY, Su FC, Chern TC, Jou IM. Ultrasonography for diagnosing carpal tunnel syndrome: a meta-analysis of diagnostic test accuracy. Ultrasound Med Biol. 2012;38(7):1121-1128.

44. Hammer HB, Hovden IA, Haavardsholm EA, Kvien TK. Ultrasonography shows increased cross-sectional area of the median nerve in patients with arthritis and carpal tunnel syndrome. Rheumatology. 2006;45(5): 584-588.

45. Miyamoto H, Miura T, Morizaki Y, Uehara K, Ohe T, Tanaka S. Comparative study on the stiffness of transverse carpal ligament between normal subjects and carpal tunnel syndrome patients. Hand Surg. 2013; 18(2):209-214

46. Ghajarzadeh M, Dadgostar M, Sarraf P, Emami-Razavi SZ, Miri S, Malek M. Application of ultrasound elastography for determining carpal tunnel syndrome severity. Jpn J Radiol. 2015;33(5):273-278.

47. Liao YY, Lee WN, Lee MR, et al. Carpal tunnel syndrome: US strain imaging for diagnosis. Radiology. 2015;275(1):205-214.

48. Roghani RS, Holisaz MT, Norouzi AAS, et al. Sensitivity of highresolution ultrasonography in clinically diagnosed carpal tunnel syndrome patients with hand pain and normal nerve conduction studies. J Pain Res. 2018;11:1319-1325.
Clinical Interventions in Aging

\section{Publish your work in this journal}

Clinical Interventions in Aging is an international, peer-reviewed journal focusing on evidence-based reports on the value or lack thereof of treatments intended to prevent or delay the onset of maladaptive correlates of aging in human beings. This journal is indexed on PubMed Central, MedLine,

\section{Dovepress}

CAS, Scopus and the Elsevier Bibliographic databases. The manuscript management system is completely online and includes a very quick and fair peer-review system, which is all easy to use. Visit http://www.dovepress. com/testimonials.php to read real quotes from published authors. 